\title{
Comparative Evaluation of the Penetration Depth into Dentinal Tubules of Three Endodontic Irrigants
}

\author{
Luciano Giardino ${ }^{1, *(1)}$, Eugenio Pedullà ${ }^{2}\left(\mathbb{D}\right.$, Francesco Cavani ${ }^{3}\left(\mathbb{D}\right.$, Francesca Bisciotti $^{4}$, Luca Giannetti $^{4}$, \\ Vittorio Checchi ${ }^{4}\left(\mathbb{D}\right.$, Daniele Angerame ${ }^{5}$, Ugo Consolo ${ }^{4}\left(\mathbb{D}\right.$ and Luigi Generali ${ }^{4, *(\mathbb{D}}$
}

1 Independent Researcher, 88900 Crotone, Italy

2 Department of General Surgery and Surgical-Medical Specialties, University of Catania, 95131 Catania, Italy; eugeniopedulla@gmail.com

3 Department of Biomedical Metabolic and Neural Sciences, Section of Human Morphology, University of Modena and Reggio Emilia, 41125 Modena, Italy; francesco.cavani@unimore.it

4 Department of Surgery, Medicine, Dentistry and Morphological Sciences with Transplant Surgery, Oncology and Regenerative Medicine Relevance (CHIMOMO), University of Modena and Reggio Emilia, 41125 Modena, Italy; frabisciotti95@gmail.com (F.B.); luca.giannetti@unimore.it (L.G.); vittorio.checchi@unimore.it (V.C.); ugo.consolo@unimore.it (U.C.)

5 University Clinical Department of Medical, Surgical and Health Sciences, University of Trieste, 34149 Trieste, Italy; d.angerame@fmc.units.it

* Correspondence: lucianogiardino057@gmail.com (L.G.); luigi.generali@unimore.it (L.G.)

\section{check for}

updates

Citation: Giardino, L.; Pedullà, E.; Cavani, F.; Bisciotti, F.; Giannetti, L.; Checchi, V.; Angerame, D.; Consolo, U.; Generali, L. Comparative

Evaluation of the Penetration Depth into Dentinal Tubules of Three Endodontic Irrigants. Materials 2021, 14, 5853. https://doi.org/10.3390/ ma14195853

Academic Editors: Ivana Miletić and Edgar Schäfer

Received: 26 August 2021

Accepted: 5 October 2021

Published: 6 October 2021

Publisher's Note: MDPI stays neutral with regard to jurisdictional claims in published maps and institutional affiliations.

Copyright: (c) 2021 by the authors. Licensee MDPI, Basel, Switzerland. This article is an open access article distributed under the terms and conditions of the Creative Commons Attribution (CC BY) license (https:/ / creativecommons.org/licenses/by/ $4.0 /)$.
Abstract: This study aimed to examine the penetration depth into dentinal tubules of some chelating agents. The 17\% EDTA and two preparations containing surfactants (Smear Clear, Bioakt Endo) were tested. Surface tension and liquid viscosity were measured using a Dynamic Contact Angle Analyzer and a Haake rotational rheometer. To measure the penetration depth inside dentinal tubules, thirty maxillary central incisors were selected from a pool of extracted human permanent teeth and allocated to three experimental groups (10 samples each), as well as were mechanically shaped and cleansed with $5.25 \% \mathrm{NaOCl}$, followed by each of the chelators being labeled with $0.1 \mathrm{wt} \%$ Rhodamine $\mathrm{B}$ according to final irrigation protocol established. The samples were embedded in an epoxy resin, after which $200 \mu \mathrm{m}$ thick transverse sections were obtained at 2, 5, and $8 \mathrm{~mm}$ from the apex with a saw microtome. The specimens were then observed using a confocal laser microscope (CLSM) and the penetration of the labeled solution was measured in every third of each sample. Statistical analysis was performed using ANOVA or Kruskal-Wallis tests according to the distribution of data, evaluated with the Shapiro-Wilk normality test. Viscosity and surface tension tests have shown that BioAKT Endo has the lowest values compared to EDTA and Smear Clear. The medium penetration depth did not significantly differ among the three irrigants, while it increased considerably from the apical to the coronal level in all groups. Additionally, the maximum penetration depth increased significantly from the apical to coronal level, while among groups, BioAKT Endo showed the highest values at the apical and middle level compared to the other irrigants. No significant differences were observed among the three groups in medium and maximum penetration depths when the entire root was considered. New irrigants containing surfactants show reduced surface tension and, in one case (BioAKT Endo), viscosity. The lowering of the surface tension allows for better penetration of liquids into dentinal tubules than EDTA alone, thus improving the cleaning of the root canal system.

Keywords: chelators; confocal laser scanning microscope; dentinal tubules; surface tension; viscosity

\section{Introduction}

The primary goal of endodontic therapy is to eradicate bacteria from the infected root canals and prevent their reinfection [1]. Matsuo et al. showed that bacteria are present in the dentinal tubules in $70 \%$ of endodontic infections [2]. Even with root canal instrumentation and disinfection, 65\% of tubules remain infected [2], acting as an important reservoir 
of microorganisms for root canal reinfection [3]. In past years, Ando and Hoshino [4] have observed varying bacterial invasion depths within dentinal tubules, ranging from 500 to $2000 \mu \mathrm{m}$. Siqueira and Rôças, while studying debridement and bacteria remaining in the root canal, regardless of the instrumentation technique used, reported low debridement and inadequate disinfection of the root canal system [5]. The antibacterial effect, achieved by endodontic treatment, is more likely affected by the degree of the penetration of irrigants to scavenge bacteria residing deeply inside infected dentinal tubules than by the instrumentation of the root canal system because the shaping protocol revealed deficient debridement and areas untouched by both the manual K-files and rotary or reciprocating instruments [6]. Due to these limitations, in recent years, research on root canal irrigation quality and efficiency has focused on irrigating solutions with better cleaning and antibacterial activity as a necessary complement to mechanical preparation. Baker et al. [7] emphasized that the use of sodium hypochlorite $(\mathrm{NaOCl})$ and ethylenediaminetetraacetic acid (EDTA) is the gold standard to dissolve necrotic tissue, remove the smear layer, and kill microorganisms in the root canal space. Nonetheless, due to their high surface tension, both irrigants do not deeply penetrate into dentinal tubules or other irregularities as isthmuses [8].

Although EDTA is the most commonly used chelator in contemporary endodontics, it has some drawbacks, such as a high surface tension [9], limiting its penetration into dentinal tubules; irregularities of the root canal system and isthmuses; and little or no antibacterial activity [10]. Conversely, a previous study reported that solutions with surface-active agents added are characterized by low surface tension [11], enhancing their antibacterial effect in line with other investigations [12,13]. One possible explanation for the increased bactericidal properties of irrigants is that incorporating different cleaning agents such as surfactants can enhance their wetting properties [14], hence their ability to penetrate more deeply into the dentinal tubules [15].

To overcome these problems, new irrigating solutions with detergents added, such as Smear Clear and more recently BioAKT Endo, have been introduced on the market to improve the clinical success rate of endodontic treatment. Smear Clear is a new class of $17 \%$ EDTA solution including a cationic cetrimide (CTR) and anionic surfactant Triton $\mathrm{X}-100$, capable of lowering its surface tension by $32.5 \%$ compared to the original formula [6]. Recently, a new endodontic irrigant containing silver ions $(0.003 \%)$ in citric acid $(4.846 \%)$, specifically BioAKT Endo, was developed for clinical use to introduce a new two-in-one irrigant as an alternative to EDTA. Previous studies have reported that acidic solutions showed more effective smear layer removal [16] and improved antimicrobial activity in the root canal system [17] than EDTA-based solutions. Perhaps these results were due to their lower $\mathrm{pH}$, which increased the removal of inorganic elements, such as calcium. Therefore, this study aimed to evaluate the surface tension and penetration depth into human dentin, and this new irrigant compared to other established solutions using a confocal laser scanning microscope (CLSM). The null hypothesis tested was that there are no significant differences in surface tension and both medium and maximum penetration depth into dentinal tubules among the irrigants employed. Moreover, preliminary laboratory measurements were performed on the three irrigants mentioned above to verify if their viscosity values could affect medium and maximum penetration depths into dentinal tubules.

\section{Materials and Methods}

This laboratory-based study evaluated the following solutions: 17\% EDTA, Smear Clear, and BioAKT Endo (Table 1). 
Table 1. Chelating agents' compositions and manufacturers.

\begin{tabular}{|c|c|c|}
\hline Chelating Agents & Compositions & Manufacturer \\
\hline EDTA & $\begin{array}{l}17 \% \text { ethylenediaminetetraacetic acid } \\
\text { water }\end{array}$ & $\begin{array}{l}\text { Ogna Laboratori Farmaceutici, Muggio, } \\
\text { Italy }\end{array}$ \\
\hline Smear Clear & $\begin{array}{c}17 \% \text { EDTA } \\
\text { Cetrimide (\% unknown) } \\
\text { Triton X-100 (\% unknown) } \\
\text { water }\end{array}$ & KerrHawe SA, Bioggio, Switzerland \\
\hline BioAKT Endo & $\begin{array}{c}4.846 \% \text { citric acid } \\
0.003 \% \text { silver ions } \\
\text { Detergents unknown } \\
\text { water }\end{array}$ & New Tech Solutions s.r.l., Brescia, Italy \\
\hline
\end{tabular}

\subsection{Surface Tension and Viscosity Measurements}

Surface tension measurements, based on the geometry of the entirely wetted glass slide in contact with the liquids under investigation, were assessed using the Wilhelmy plate technique by the Cahn DCA-322 Dynamic Contact Angle Analyzer (Gibertini Elettronica, Novate (MI), Italy) as previously reported [18]. Each sample was measured five times to calculate the mean and standard deviation (SD). In addition, a preliminary pilot study was carried out on the three chelants to determine their viscosity using a Thermo Scientific RS100 Haake rotational rheometer (Thermo Fisher Scientific, Rodano, Italy) regulated at speeds of 100-1000 s ${ }^{-1}$ (https:/ / www.drugfuture.com/Pharmacopoeia/EP7/DATA/2021 OE.PDF, accessed on 7 July 2021) [19]. Measurements were achieved at room temperature $\left(21^{\circ} \mathrm{C}\right)$ for each sample.

\subsection{Sample Selection and Experimental Procedures}

Thirty maxillary central incisors with single round-shape root canals with fully formed apices and straight canals between $0^{\circ}$ and $5^{\circ}$ were selected from a pool of extracted teeth and stored in a $0.1 \%$ thymol solution at $5{ }^{\circ} \mathrm{C}$ for no longer than 15 days. According to the Italian legislation, written informed consent for the use of teeth for research purposes was collected from all patients. The crown of each tooth was removed using a 701 high-speed fissure bur (Komet Italia, Milano, Italy) under water spray to obtain a working length (WL) at $14 \pm 1 \mathrm{~mm}$. Radiographs were taken in a mesiodistal and buccolingual plane with a size $10 \mathrm{~K}$-file (Dentsply Maillefer, Baillagues, Switzerland) inserted into the canal to verify the straightening and select only teeth with a round canal, with a long:short cross-sectional diameter ratio of $\leq 2.5,5 \mathrm{~mm}$ from the apex [20]. The working length (WL) and apical foramen patency were verified by insertion of a size $10 \mathrm{~K}$-File (Dentsply Maillefer, Baillagues, Switzerland) until its tip appeared at the apical foramen under microscopic vision at 10× (OPMI Pico, Carl Zeiss Meditec Inc., Jena, Germany) [21], which then subtracting $0.5 \mathrm{~mm}$. The specimens were divided into three experimental groups (n $=10$ per group). The groups were homogeneous for canal width (Anova, $\mathrm{P}>0.05$ ) [22] A mechanical glide path was performed with WaveOne Gold Glider reciprocating single files (size 0.15 and taper 0.017 to 0.085 at D16) (Dentsply Maillefer, Baillagues, Switzerland). Each root canal was instrumented with Wave One Gold Medium (size 0.35, taper 0.06) and then with WaveOne Gold Large (size 0.45, taper 0.07) (Dentsply Maillefer, Baillagues, Switzerland). The instruments were used in a slow in-and-out pecking motion mounted on an X-Smart plus endodontic engine (Dentsply Maillefer, Baillagues, Switzerland) set in the "WAVE ONE ALL" mode up to $1 \mathrm{~mm}$ from the WL. Working length was re-checked with a size $10 \mathrm{~K}$-File and eventually the instruments were used at full WL. At each instrument changeover, each canal was rinsed with $1 \mathrm{~mL}$ of $5.25 \% \mathrm{NaOCl}$ (Niclor, Ogna, Muggiò, Italy) using a syringe with a 30-gauge side-vented needle (Max-i-Probe; Dentsply Rinn, Elgin, IL, USA) placed before the binding point but no closer than $2 \mathrm{~mm}$ to the WL. For each sample, a total of $10 \mathrm{~mL}$ of $5.25 \% \mathrm{NaOCl}$ was used. The outer surface of the teeth was dried with 
paper towels and at the apical third, it was covered with a thin layer of dual composite (Opticore classic, IDS Spa, Savona, Italy).

In one group, the canals were finally rinsed with $5 \mathrm{~mL}$ of Smear Clear and in the others, with $5 \mathrm{~mL}$ of BioAKT Endo and with $5 \mathrm{~mL}$ of $17 \%$ EDTA: these irrigant solutions were labeled with $0.1 \%$ wt Rhodamine B dye (CARLO ERBA Reagenti S.r.l, Arese, Italy) and delivered using a syringe with a 25-gauge side-vented needle (Hawe Irrigation Probe, Kerr Corporation, Orange, CA, USA) placed at $2 \mathrm{~mm}$ from the WL. All chelating solutions were left in place for $3 \mathrm{~min}$ [23] and then the canals were dried with WaveOne Gold Large paper point (Dentsply, Maillefer, Baillagues, Switzerland).

Teeth were embedded in a room temperature-setting epoxy resin (Hard Rock 554, Remet, Bologna, Italy) and $200 \mu \mathrm{m}$ thick transverse sections were obtained at 2, 5, and $8 \mathrm{~mm}$ from the apex with a saw microtome (Leica SP 1600, Nussloch, Germany). All sections were observed with a Leica TCS SP8 AOBS confocal microscope equipped with a White Light Laser (Mannheim, Germany) using the specific wavelengths for Rhodamine B and images were acquired using a $10 \times$ objective. Image mosaics were acquired and merged using the Navigator tool. Each image was obtained performing $20 \mu \mathrm{m}$ z-stacks with one $\mu \mathrm{m}$ step size. The medium penetration depth of the irrigant solution into dentinal tubules was calculated as the average penetration measured at eight standardized points with the straight-line tool of the Fiji software (National Institutes of Health, Bethesda, MD, USA), starting from the inner side of the canal wall at 2,5, and $8 \mathrm{~mm}$ level from the apex for each section [22]. The maximum penetration depth was measured as the deepest point of penetration from the canal wall at 2,5, and $8 \mathrm{~mm}$ levels from the apex for each section, according to the observer [22].

\subsection{Statistical Analysis}

The normal distribution of all data obtained was evaluated with the Shapiro-Wilk normality test. When data were normally distributed, the comparison among groups and root levels within the same group were performed with the ANOVA test followed by Bonferroni's post-hoc test. If not normally distributed, the non-parametric Kruskal-Wallis test followed by the Dunn test was used; $p$ values $<0.05$ were considered significant. Stata 11 software (StataCorp LLC, College Station, TX, USA) was used for the analysis.

\section{Results}

Our preliminary viscosity tests showed that BioAKT Endo had a viscosity value of $1.2 \mathrm{mPa}$ s while Smear Clear and $17 \%$ EDTA had similar viscosities $(2 \mathrm{mPa} s)$ at $20^{\circ} \mathrm{C}$.

\subsection{Surface Tension}

Table 2 summarizes the surface tension evaluation results with the Wilhelmy plate technique. The $17 \%$ EDTA solution had the highest surface tension value compared to all other solutions $(p<0.001)$, while Bioakt Endo had the lowest one. In addition, a significant difference was observed between BioAKT Endo and Smear Clear $(p<0.05)$.

Table 2. Surface tension values $\left(\mathrm{mJ} / \mathrm{m}^{2}\right)$ of the irrigating solutions.

\begin{tabular}{ccc}
\hline Solutions & Number of Samples & Surface Tension Mean Value \pm SD \\
\hline 17\% EDTA & 5 & $* 48.9 \pm 0.65$ \\
Smear Clear & 5 & $33.00 \pm 0.62$ \\
BioAKT Endo & 5 & $* * 32.00 \pm 0.59$ \\
\hline${ }^{*} p<0.001$ vs. BioAKT Endo and Smear Clear; ${ }^{* *} p<0.05$ vs. Smear Clear (Kruskal-Wallis).
\end{tabular}

\subsection{Penetration Depth into Dentinal Tubules}

Means and standard deviations relative to the irrigant medium penetration are reported in Table 3. No significant differences could be found among the three irrigants employed when the same root levels were compared or even when considering the whole root altogether; nonetheless, BioAKT Endo showed the highest values among the three 
groups. Within each group, a significant increase in the medium penetration depth was observed from apical to coronal sections.

Table 3. Medium penetration of irrigants ( $\mu \mathrm{m}$, mean \pm s.d.).

\begin{tabular}{cccc}
\hline Sample Level & Smear Clear & BioAKT Endo & EDTA \\
\hline Apical & $82 \pm 89$ & $172 \pm 229$ & $63 \pm 75$ \\
Middle & $361 \pm 183^{*}$ & $606 \pm 527^{*}$ & $516 \pm 404^{*}$ \\
Coronal & $911 \pm 420 * * *$ & $1067 \pm 485^{* * *}$ & $952 \pm 313^{* * * *}$ \\
Total & $451 \pm 436$ & $615 \pm 560$ & $511 \pm 468$ \\
\hline${ }^{*} p<0.05$ vs. apical of same group; ${ }^{* *} p<0.05$ vs. middle of same group (Kruskal-Wallis).
\end{tabular}

Figure 1 shows an overview of representative CLSM images from three experimental groups at 2, 5, and $8 \mathrm{~mm}$ levels.

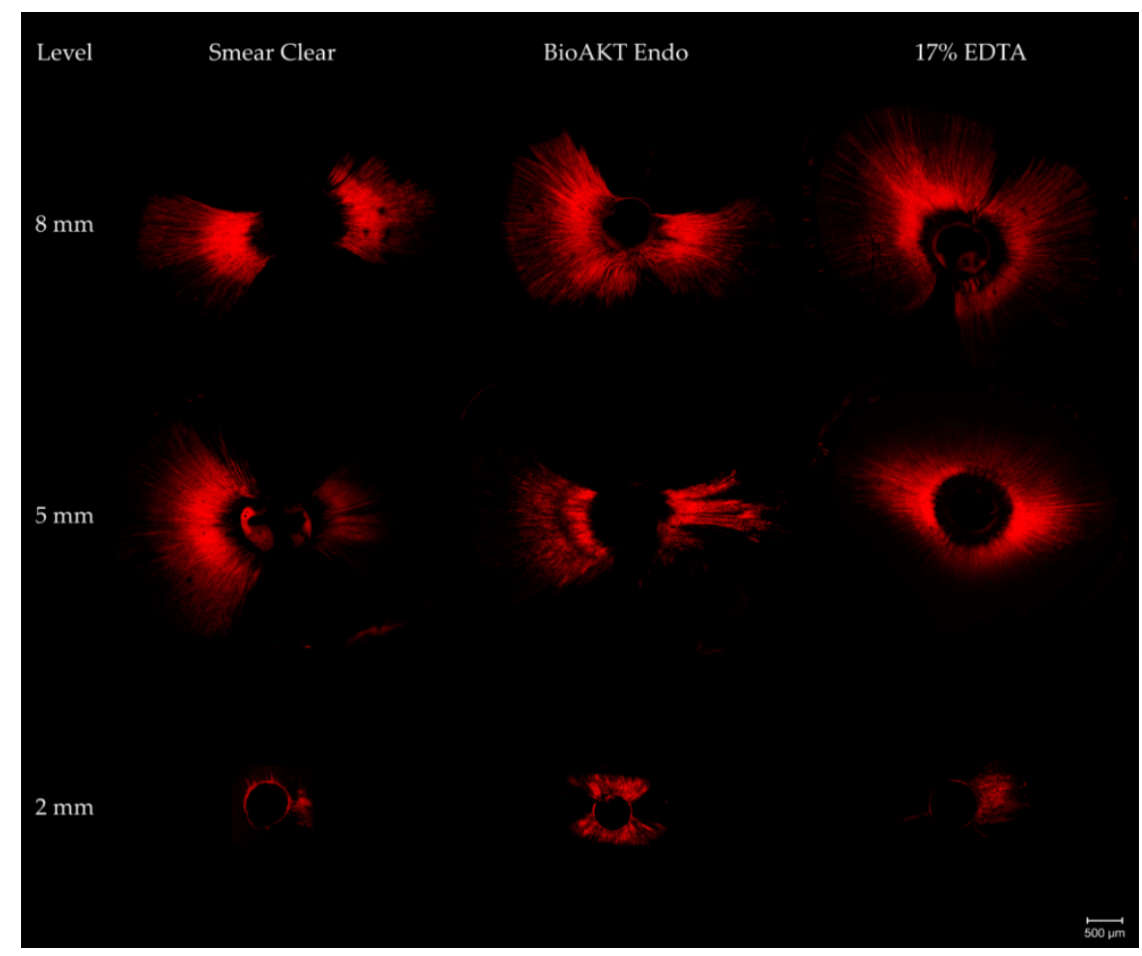

Figure 1. Representative images of the evaluated groups.

As for the maximum penetration depth, data are reported in Table 4. At the apical level, the BioAKT Endo group had the highest values compared to the other groups. In particular, it was significantly higher than the EDTA values.

Table 4. Maximum penetration of irrigants ( $\mu \mathrm{m}$, mean \pm s.d.).

\begin{tabular}{cccc}
\hline Sample Level & Smear Clear & BioAKT Endo & EDTA \\
\hline Apical & $329 \pm 240$ & $508 \pm 459 \S$ & $129 \pm 147$ \\
Middle & $1339 \pm 517^{\S}, *$ & $1351 \pm 822 \S \S, *$ & $874 \pm 458^{*}$ \\
Coronal & $2022 \pm 439^{*, * *}$ & $1942 \pm 617^{*}$ & $1543 \pm 300^{* * * *}$ \\
Total & $1230 \pm 813$ & $1267 \pm 867$ & $849 \pm 666$ \\
\hline
\end{tabular}

$\S p<0.05$ vs. EDTA apical; $\$ \S p<0.05$ vs. EDTA middle (ANOVA). ${ }^{*} p<0.05$ vs. Apical of the same group; ${ }^{* *} p<0.05$ vs. middle of same group (Kruskal-Wallis).

At the middle level, both the BioAKT Endo and Smear Clear groups showed significantly higher maximum penetration depths with respect to that of the EDTA. No significant differences were recorded at the coronal level among groups. When the entire root was 
considered, no significant differences were observed among the three groups regarding the maximum penetration depth. The maximum penetration depth increased significantly from the apical to the coronal level in each group.

\section{Discussion}

In the present study, the surface tension and penetration depth of some irrigating solutions containing EDTA or citric acid were evaluated inside dentine tubules in human teeth.

Smear Clear is a 17\% EDTA irrigant containing the cationic detergent cetrimide (CTR) and one additional non-ionic surfactant Triton X-100. BioAKT Endo, instead, is a silver citrate solution wherein silver ions are weakly bonded to citric acid. Besides a good ability to remove the smear layer, both solutions demonstrated significant antibacterial activity $[12,24,25]$. Previous reports highlighted that incorporating detergents into irrigants could reduce their surface tension, enhance the solution's wettability, and improve the root canal system disinfection [26]. Wettability has been defined as the tendency of a fluid to spread over or adhere to a solid surface as dentin. This feature is necessary for the irrigant to penetrate the root canal system cavities, depending on the surface tension [27]. In the present study, we found that the surface tension values of both $17 \%$ EDTA and citric acid-based chemical agents with detergents added were lower than the $17 \%$ EDTA alone (Table 1), confirming previous investigations [8,25]. The null hypothesis concerning the surface tension of the irrigants tested must be rejected as BioAKT and Smear Clear showed a lower surface tension than EDTA. Conversely, the penetration depth of the chelators mentioned above have not yet been evaluated. For this reason, this investigation was mainly designed to assess the penetration depth into dentinal tubules of the chemical agents herein used as final irrigating solutions. To date, there is only one investigation concerning the sealer penetration of silver citrate solutions [24], in which the labeled sealer with a fluorescent dye was used as an indicator of sealer-filled root canal dentin treated with the silver citrate solution compared to other irrigants. Instead, no studies are available in the literature concerning the penetration depth of these new chelating agents into dentinal tubules. Our results indicate higher penetration depths in the coronal and middle thirds of specimens from all the groups; additionally, a lower penetration was seen in the apical third of all the root canals analyzed (Table 2). As for medium penetration, since no significant differences emerged among the irrigants, the null hypothesis must be accepted, although it must also be rejected for the maximum penetration depth as BioAKT Endo and Smear Clear had significantly better performances. Current results could be explained by the fact that the anatomical structure of the root canal system can influence irrigants' penetration depth into dentinal tubules. Indeed, dentinal tubules in the apical third of the root canals are less permeable than those in the coronal and middle thirds due to tubular sclerosis, the smaller diameter, and the reduced number [28]. After the age of 30, dentinal sclerosis develops, starting from the apical third of teeth leading to the "butterfly effect" [22,29]. This optical effect leads to the obliteration (sclerosis) of most dentinal tubules in the mesial and distal directions. The great variability observed probably depends on the age of patients that were not selected according to a specific age range; on the contrary, age was unknown. This fact, strictly linked to the butterfly effect, could explain the great variability and standard deviation observed in all the groups and regions analyzed. Furthermore, it was highlighted that the constriction of the root canal apical third hinders the flow and backflow of irrigating solutions, compromising its cleaning [30], probably because the narrowing would inhibit the needle placement inside the apical third and the resultant fluid dynamics [31]. BioAKT Endo showed greater medium penetration depth, although not significantly, than 17\% EDTA and Smear Clear in all the thirds of the root canals (Table 3). These results could be explained by the chelators' different surface tensions, viscosities, molecular weights, and $\mathrm{pH}$ values. EDTA showed a significantly higher surface tension value (Table 2) and a lower maximum penetration depth (Table 4) than other irrigant solutions. As for the similar penetration recorded at the apical level in both the EDTA and Smear Clear groups, it must be underlined that their similar viscosity could have greatly 
affected the penetration in this area of the root where dentinal sclerosis greatly reduces the diameter of the tubules. In fact, besides surface tension, an essential aspect of irrigant flow is its viscosity, affecting the irrigant penetration and its flow within the root canal [32]. Studies have shown increased tubular penetration with decreased viscosity and surface tension [32]. According to the present study results, BioAKT Endo (citric acid-based chelator) viscosity was lower than both EDTA solutions, regardless of the presence or absence of detergents. The viscosity of a solution is related to its molecular weight, affecting the liquid flow and its penetration in dentinal tubules [33,34]. With its lower molecular weight (https: / / pubchem.ncbi.nlm.nih.gov/compound/Citric-acid, accessed on 7 July 2021), citric acid can easily penetrate deeper into dentinal tubules than EDTA, the highest molecular weight chelator (https:/ / pubchem.ncbi.nlm.nih.gov/compound/EDTA-disodium-salt, accessed on 7 July 2021). Furthermore, larger molecules as EDTA bind to fewer calcium ions in dentin [35]. Concerning the action of each solution related to its composition and $\mathrm{pH}$, a report highlighted that using a low concentration (5\%) of citric acid at acidic $\mathrm{pH}$, similar to the BioAKT Endo composition, is adequate to remove the smear layer as efficiently as done for higher concentrations [36]. Moreover, Poggio et al. [37] compared the decalcifying capacity of different irrigating solutions at different contact times, observing a significantly higher release of calcium $\left(\mathrm{Ca}^{++}\right)$in samples exposed to citric acid-based agents than that of EDTA solutions. The higher release reported in that study may be related to the lower $\mathrm{pH}$ of the citric acid solutions $(\mathrm{pH}<2)$, thus increasing the removal of inorganic elements such as $\mathrm{Ca}^{++}$from the hydroxyapatite crystals. The addition of detergents did not affect the extraction properties of EDTA and citric acid solutions because the values of the concentration of $\mathrm{Ca}^{++}$released in the two solutions did not significantly differ. Therefore, the addition of surfactants to EDTA (i.e., Smear Clear) does not seem to alter its viscosity, although it has a profound effect on surface tension, which is extremely reduced, making it similar to BioAKT Endo. Sousa and Silva [38] have shown that $1 \%$ citric acid solution at $\mathrm{pH} 1.0$ removed more calcium than $\mathrm{pH}$ 7.4. Conversely, there were no differences between $1 \%$ citric acid at $\mathrm{pH} 7.4$ and saline solution, which had the least efficacy for $\mathrm{Ca}^{++}$extraction. Citric acid monopolizes such a large portion of the solvent at high concentrations that the amount of solvent available for $\mathrm{Ca}^{++}$diffusion is dramatically reduced [38]. Then, the $\mathrm{pH}$ of the citric acid solution becomes a more important factor in demineralization than concentration [39]. The lower ability of EDTA compared to citric acid in removing the smear layer can be explained by the fact that EDTA properties are self-limiting due to its neutral $\mathrm{pH}$ [40]. Since $99 \%$ of EDTA exists as EDTAHNa 3 (trisodium EDTA), the exchange of $\mathrm{Ca}^{++}$from dentin will occur by $\mathrm{H}^{+}$ions and subsequently decrease in $\mathrm{pH}$, hence increasing in acidity; therefore, the effect of EDTA decreases with the increase in acidity. Unlike EDTA, acidic chelators instead depend on the hydrogen ion concentration for their demineralization effects as organic acids [35]. Pending further clinical and safety studies, other studies on these new chelators combined with detergents should be undertaken to confirm the efficacy and safety of these agents for root canal therapy in daily clinical practice.

\section{Conclusions}

Under these experimental conditions and within the limits of the present study, BioAKT and Smear Clear showed a lower surface tension than EDTA. As for the medium penetration, no significant differences emerged among the irrigants, while BioAKT Endo and Smear Clear had significantly better performances than EDTA at the apical and middle levels for maximum penetration depth. The presence of surfactants, lowering the surface tension of irrigants, can improve their maximum penetration, irrespective of their viscosity value. These characteristics should be considered to enhance the cleaning of root canal walls and dentinal tubules.

Author Contributions: Conceptualization, L.G. (Luciano Giardino) and L.G. (Luigi Generali); methodology, L.G. (Luigi Generali), F.C., V.C. and F.B.; validation, L.G. (Luciano Giardino), U.C., E.P. and D.A.; investigation, F.B., F.C. and L.G. (Luigi Generali); data curation, E.P. and F.B.; writing-original 
draft preparation, L.G. (Luciano Giardino), L.G. (Luigi Generali) and F.C.; writing-review and editing, E.P., V.C., L.G. (Luciano Giardino), U.C., D.A. and L.G. (Luca Giannetti); visualization, F.C. and L.G. (Luigi Generali); supervision, L.G. (Luca Giannetti) and U.C.; project administra-tion, L.G. (Luciano Giardino); funding acquisition, Luigi Generali. All authors have read and agreed to the published version of the manuscript.

Funding: This research study was funded by the FAR project (University of Modena and Reggio Emilia Funds for Research) entitled Microstructural and Mechanical investigation of Nickel-Titanium Endodontic instruments (MMiNTEndo).

Institutional Review Board Statement: Not applicable.

Informed Consent Statement: A written informed consent for the use of teeth for research purposes was collected from all subjects.

Data Availability Statement: The data presented in this study are available on request from the corresponding author.

Acknowledgments: The Confocal Laser Scanning microscope is available at the imaging facility (Centro Interdipartimentale Grandi Strumenti (CIGS) of the University of Modena and Reggio Emilia). We thank Cinzia Restani and Jonathan Vinet from CIGS for their technical support, and Fernanda Andreola of the University of Modena and Reggio Emilia for the viscosity tests.

Conflicts of Interest: The authors declare no conflict of interest.

\section{References}

1. Wong, J.; Manoil, D.; Näsman, P.; Belibasakis, G.N.; Neelakantan, P. Microbiological Aspects of Root Canal Infections and Disinfection Strategies: An Update Review on the Current Knowledge and Challenges. Front. Oral. Health 2021, $2,672887$. [CrossRef]

2. Matsuo, T.; Shirakami, T.; Ozaki, K.; Nakanishi, T.; Yumoto, H.; Ebisu, S. An immunohistological study of the localization of bacteria invading root pulpal walls of teeth with periapical lesions. J. Endod. 2003, 29, 194-200. [CrossRef] [PubMed]

3. Oguntebi, B.R. Dentine tubule infection and endodontic therapy implications. Int. Endod. J. 1994, 27, 218-222. [CrossRef] [PubMed]

4. Ando, N.; Hoshino, E. Predominant obligate anaerobes invading the deep layers of root canal dentine. Int. Endod. J. 1990, 23, 20-27. [CrossRef] [PubMed]

5. Siqueira, J.F.; Rôças, I.N. Clinical implications and microbiology of bacterial persistence after treatment procedures. J. Endod. 2008, 34, 1291-1301. [CrossRef]

6. Peters, O.A.; Laib, A.; Göhring, T.N.; Barbakow, F. Changes in Root Canal Geometry after Preparation Assessed by HighResolution Computed Tomography. J. Endod. 2001, 27, 1-6. [CrossRef]

7. Baker, N.A.; Eleazer, P.D.; Averbach, R.E.; Seltzer, S. Scanning electron microscopic study of various irrigation solutions' efficacy. J. Endod. 1975, 1, 127-135. [CrossRef]

8. Giardino, L.; Ambu, E.; Becce, C.; Rimondini, L.; Morra, M. Surface tension comparison of four common root canal irrigants and two new irrigants containing antibiotic. J. Endod. 2006, 32, 1091-1093. [CrossRef]

9. Giardino, L.; Savadori, P.; Generali, L.; Mohammadi, Z.; Del Fabbro, M.; De Vecchi, E.; Bidossi, A. Antimicrobial effectiveness of etidronate powder (Dual Rinse ${ }^{\circledR}$ HEDP) and two EDTA preparations against Enterococcus faecalis: A preliminary laboratory study. Odontology 2020, 108, 396-405. [CrossRef]

10. Arias-Moliz, M.T.; Ferrer-Luque, C.M.; Espigares-García, M.; Baca, P. Enterococcus faecalis biofilms eradication by root canal irrigants. J. Endod. 2009, 35, 711-714. [CrossRef]

11. Ferrer-Luque, C.M.; Arias-Moliz, M.T.; González-Rodríguez, M.P.; Baca, P. Antimicrobial activity of maleic acid and combinations of cetrimide with chelating agents against Enterococcus faecalis biofilm. J. Endod. 2010, 36, 1673-1675. [CrossRef]

12. Dunavant, T.R.; Regan, J.D.; Glickman, G.N.; Solomon, E.S.; Honeyman, A.L. Comparative evaluation of endodontic irrigants against Enterococcus faecalis biofilms. J. Endod. 2006, 32, 527-531. [CrossRef]

13. Ferrer-Luque, C.M.; Conde-Ortiz, A.; Arias-Moliz, M.T.; Valderrama, M.J.; Baca, P. Residual activity of chelating agents and their combinations with cetrimide on root canals infected with Enterococcus faecalis. J. Endod. 2012, 38, 826-828. [CrossRef]

14. Glantz, P.O.; Hansson, L. Wetting of dentine by some root canal medicaments. Odontol. Revy 1972, 23, 205-210. [PubMed]

15. Wang, Z.; Shen, Y.; Ma, J.; Haapasalo, M. The effect of detergents on the antibacterial activity of disinfecting solutions in dentin. J. Endod. 2012, 38, 948-953. [CrossRef] [PubMed]

16. Banode, A.M.; Gade, V.; Patil, S.; Chandhok, D.; Sinkar, R. Comparative scanning electron microscopy evaluation of smear layer removal with $17 \%$ ethylenediaminetetraacetic acid, $10 \%$ citric acid and newer irrigant QMix: In vitro study. Indian J. Oral Health Res. 2015, 1, 56-61. [CrossRef]

17. Georgopoulou, M.; Kontakiotis, E.; Nakou, M. Evaluation of the antimicrobial effectiveness of citric acid and sodium hypochlorite on the anaerobic flora of the infected root canal. Int. Endod. J. 1994, 27, 139-143. [CrossRef] 
18. Giardino, L.; Del Fabbro, M.; Morra, M.; Pereira, T.; Bombarda de Andrade, F.; Savadori, P.; Generali, L. Dual Rinse ${ }^{\circledR}$ HEDP increases the surface tension of $\mathrm{NaOCl}$ but may increase its dentin disinfection efficacy. Odontology 2019, 107, 521-529. [CrossRef]

19. Council of Europe. Viscosity-rotating viscometer method. In European Pharmacopoeia, 8th ed.; Directorate for the Quality of Medicines \&Health Care of the Council of Europe (EDQM): Strasbourg, France, 2014; pp. 27-30.

20. De-Deus, G.; Barino, B.; Marins, J.; Magalhães, K.; Thuanne, E.; Kfir, A. Self-adjusting file cleaning-shaping-irrigation system optimizes the filling of oval-shaped canals with thermoplasticized gutta-percha. J. Endod. 2012, 38, 846-849. [CrossRef]

21. Generali, L.; Puddu, P.; Borghi, A.; Brancolini, S.; Lusvarghi, L.; Bolelli, G.; Consolo, U.; Pedullà, E. Mechanical properties and metallurgical features of new and ex vivo used Reciproc Blue and Reciproc. Int. Endod. J. 2020, 53, 250-264. [CrossRef]

22. Generali, L.; Prati, C.; Pirani, C.; Cavani, F.; Gatto, M.R.; Gandolfi, M.G. Double dye technique and fluid filtration test to evaluate early sealing ability of an endodontic sealer. Clin. Oral Investig. 2017, 21, 1267-1276. [CrossRef]

23. Martinelli, S.; Alburquerque, G.; Silva, L. Effect of EDTAC and citric acid on dentinal walls. Variation of exposure time and dental age. Odontoestomatología 2019, 21, 5-15.

24. Tonini, R.; Giovarruscio, M.; Gorni, F.; Ionescu, A.; Brambilla, E.; Mikhailovna, I.M.; Luzi, A.; Maciel Pires, P.; Sauro, S. In Vitro Evaluation of Antibacterial Properties and Smear Layer Removal/Sealer Penetration of a Novel Silver-Citrate Root Canal Irrigant. Materials 2020, 13, 194. [CrossRef] [PubMed]

25. Generali, L.; Bertoldi, C.; Bidossi, A.; Cassinelli, C.; Morra, M.; Del Fabbro, M.; Savadori, P.; Ballal, N.V.; Giardino, L. Evaluation of Cytotoxicity and Antibacterial Activity of a New Class of Silver Citrate-Based Compounds as Endodontic Irrigants. Materials 2020, 13, 5019. [CrossRef] [PubMed]

26. Giardino, L.; Estrela, C.; Mohammadi, Z.; Generali, L.; Asgary, S. The in vitro Effect of Irrigants with Low Surface Tension on Enterococcus faecalis. Iran. Endod. J. 2015, 10, 174-178.

27. Giardino, L.; Morra, M.; Becce, C.; Pappen, F.G.; Mohammadi, Z.; Palazzi, F. Comparative wettability of different sodium hypochlorite solutions. G. It. Endod. 2012, 26, 57-62. [CrossRef]

28. Paqué, F.; Luder, H.U.; Sener, B.; Zehnder, M. Tubular sclerosis rather than the smear layer impedes dye penetration into the dentine of endodontically instrumented root canals. Int. Endod. J. 2006, 39, 18-25. [CrossRef]

29. Russel, A.A.; Chandler, N.P.; Haumann, C.; Siddiqui, A.Y.; Tompkins, G.R. The butterfly effect: An investigation of sectioned roots. J. Endod. 2013, 39, 208-210. [CrossRef] [PubMed]

30. Küçük, M.; Kermeoğlu, F. Efficacy of different irrigation methods on dentinal tubule penetration of Chlorhexidine, QMix and Irritrol: A confocal laser scanning microscopy study. Aust. Endod. J. 2019, 45, 202-208. [CrossRef]

31. Gopikrishna, V.; Ashok, P.; Pradeep Kumar, A.P.; Narayanan, L.L. Influence of temperature and concentration on the dynamic viscosity of sodium hypochlorite in comparison with 17\% EDTA and $2 \%$ chlorhexidine gluconate: An in vitro study. J. Conserv. Dent. 2014, 17, 57-60.

32. Bukiet, F.; Soler, T.; Guivarch, M.; Camps, J.; Tassery, H.; Cuisinier, F.; Candoni, N. Factors affecting the viscosity of sodium hypochlorite and their effect on irrigant flow. Int. Endod. J. 2013, 46, 954-961. [CrossRef] [PubMed]

33. Heling, I.; Chandler, N.P. Antimicrobial effect of irrigant combinations within dentinal tubules. Int. Endod. J. 1998, 31, 8-14. [CrossRef] [PubMed]

34. Rohm, H.; Jaros, D. Analytical Methods I Principles and Significance in Assessing Rheological and Textural Properties. In Encyclopedia of Dairy Sciences, 2nd ed.; Academic Press: Cambridge, MA, USA, 2011; pp. 264-271. [CrossRef]

35. Jaiswal, S.; Patil, V.; Satish Kumar, K.S.; Ratnakar, P.; Rairam, S.; Tripathi, S. Comparative analysis of smear layer removal by conventional endodontic irrigants with a newly experimented irrigant-fumaric acid: A scanning electron microscopic study. J. Conserv. Dent. 2018, 21, 419-423. [CrossRef] [PubMed]

36. Haznedaroğlu, F. Efficacy of various concentrations of citric acid at different $\mathrm{pH}$ values for smear layer removal. Oral Surg. Oral Med. Oral Pathol. Oral Radiol. Endod. 2003, 96, 340-344. [CrossRef]

37. Poggio, C.; Dagna, A.; Vinci, A.; Beltrami, R.; Cucca, L.; Giardino, L. Decalcifying capability of irrigating solutions on root canal dentin mineral content. Contemp. Clin. Dent. 2015, 6, 201-205. [CrossRef]

38. Sousa, S.M.; Silva, T.L. Demineralization effect of EDTA, EGTA, CDTA and citric acid on root dentin: A comparative study. Braz Oral Res. 2005, 19, 188-192. [CrossRef]

39. Sterrett, J.D.; Delaney, B.; Rizkalla, A.; Hawkins, C.H. Optimal citric acid concentration for dentinal demineralization. Quintessence Int. 1991, 22, 371-375.

40. Hülsmann, M.; Heckendorff, M.; Lennon, A. Chelating agents in root canal treatment: Mode of action and indications for their use. Int. Endod. J. 2003, 36, 810-830. [CrossRef] 